\title{
Gallium doping in transparent conductive ZnO thin films prepared by chemical spray pyrolysis
}

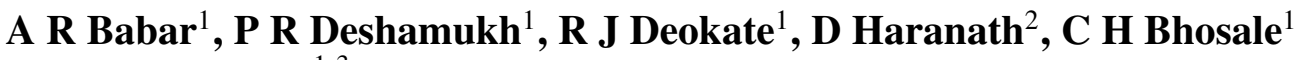 \\ and K Y Rajpure ${ }^{1,3}$ \\ ${ }^{1}$ Electrochemical Materials Laboratory, Department of Physics, Shivaji University, Kolhapur 416 004, \\ India \\ ${ }^{2}$ National Physical Laboratory, Dr K S Krishnan Road, New Delhi 110 012, India \\ E-mail: rajpure@yahoo.com
}

Received 18 April 2008, in final form 9 May 2008

Published 10 June 2008

Online at stacks.iop.org/JPhysD/41/135404

\begin{abstract}
Zinc oxide $(\mathrm{ZnO})$ and $\mathrm{ZnO}$ : Ga films have been deposited by the spray pyrolysis method onto preheated glass substrates using zinc acetate and gallium nitrate as precursors for $\mathrm{Zn}$ and $\mathrm{Ga}$ ions, respectively. The effect of Ga doping on the structural, morphological, optical and electrical properties of sprayed $\mathrm{ZnO}$ thin films were investigated using $\mathrm{X}$-ray diffraction (XRD), scanning electron microscopy, optical absorption, photoluminescence (PL) and Hall effect techniques. XRD studies reveal that films are polycrystalline with hexagonal (wurtzite) crystal structure. The thin films were oriented along the $\left(\begin{array}{lll}0 & 0 & 2\end{array}\right)$ plane. Room temperature PL measurements indicate that the deposited films exhibit proper doping of $\mathrm{Ga}$ in $\mathrm{ZnO}$ lattice. The average transparency in the visible range was around $\sim 85-95 \%$ for typical thin film deposited using 2 at $\%$ gallium doping. The optical band gap increased from 3.31 to $3.34 \mathrm{eV}$ with $\mathrm{Ga}$ doping of 2 at $\%$. The addition of gallium induces a decrease in electrical resistivity of the $\mathrm{ZnO}$ : Ga films up to 2 at $\%$ gallium doping. The highest figure of merit observed in this present study was $3.09 \times 10^{-3} \mathrm{~cm}^{2} \Omega^{-1}$.
\end{abstract}

(Some figures in this article are in colour only in the electronic version)

\section{Introduction}

Transparent conducting oxide (TCO) $\mathrm{ZnO}$ thin films are emerging as the most attractive alternative to ITO and various other TCOs [1-4]. $\mathrm{ZnO}$ has received considerable attention for its possible applications in UV light emitters, spin functional devices, gas sensors, transparent electronics and surface acoustics wave devices. While synthesizing TCO thin films, it is a common practice to introduce impurities such as In, Al, Ga, $\mathrm{N}, \mathrm{P}$, As and $\mathrm{F}$ [5], within $\mathrm{ZnO}$ thin films in order to enhance the optoelectronic properties. $\mathrm{ZnO}: \mathrm{Ga}(\mathrm{GZO})$ thin films have been deposited by several techniques such as molecular beam epitaxy [6], pulsed laser deposition [7], sintering [8], chemical spray $[9,10]$, rf magnetron sputtering [11], ion plating [12] and solid state reaction [13]. Photoluminescence (PL) and

\footnotetext{
${ }^{3}$ Author to whom any correspondence should be addressed.
}

photocurrent measurements were carried out to study the emission and absorption properties of the Ga-doped $\mathrm{ZnO}$ film [6]. Both spectra were consistent with each other showing a good response in the ultraviolet region and weak response in the green-yellow band. Dependences of structural and electrical properties on the thickness of polycrystalline Ga-doped $\mathrm{ZnO}$ thin films prepared by reactive plasma deposition [7] were reported by Yamada et al. It was observed that increasing thickness below $100 \mathrm{~nm}$ induces changes in the structural and electrical properties of the GZO films. Raman spectroscopy was used to investigate local structural properties [12] in Ga-doped $\mathrm{ZnO}$ thin films prepared at various oxygen partial pressures by the ion plating method. Raman spectra of typical film revealed the $A_{1}(L O)$ and local vibrational modes associated with $\mathrm{V}_{\mathrm{O}}$ and $\mathrm{Ga}_{\mathrm{Zn}}$, indicating that dominant defect species were $\mathrm{GaZn}_{\mathrm{Zn}}$ and $\mathrm{V}_{\mathrm{O}}$ in GZO films. Among these 
the chemical spray pyrolysis technique is simple, low cost and can be used effectively for large area deposition and film properties can be tailored by controlling the spraying conditions.

Gomez and Olvera [10] have reported the effect of deposition temperature, dopant concentration and vacuumthermal treatment on the electrical, optical, structural and morphological properties of spray deposited Ga-doped $\mathrm{ZnO}$ thin films. A minimum electrical resistivity value, of the order of $7.4 \times 10^{-3} \Omega \mathrm{cm}$, and optical transparency of the order of $80 \%$ were achieved under the optimal deposition conditions (substrate temperature $=698 \mathrm{~K},[\mathrm{Ga} / \mathrm{Zn}]=2$ at $\%$ ). The maximum figure of merit obtained for the vacuum-annealed $\mathrm{ZnO}$ : Ga films was $5.13 \times 10^{-4} \Omega^{-1}$. In order to produce improved quality $\mathrm{ZnO}: \mathrm{Ga}$ films with the spray pyrolysis technique, we have adopted the same preparative conditions reported by Gomez and Olvera [10], except especially, the source for Ga doping (gallium nitrate in this case) for gallium pentanedionate. Therefore, in this work, the influence of gallium doping on the structural, morphological, optical and electrical properties of $\mathrm{ZnO}$ films by the chemical spray technique are reported. We were able to produce better quality $\mathrm{ZnO}$ : Ga films having higher transmittance (85-95\%) and lower resistivity $\left(\sim 10^{-4} \Omega \mathrm{cm}\right)$.

\section{Experimental}

Zinc oxide $(\mathrm{ZnO})$ thin films were deposited onto ultrasonically cleaned preheated Corning glass substrates using the chemical spray pyrolysis technique. Spraying solution (0.2 M) was prepared by mixing the appropriate volumes of zinc acetate $\left(\mathrm{Zn}\left(\mathrm{CH}_{3} \mathrm{COO}\right)_{2} \cdot 2\left(\mathrm{H}_{2} \mathrm{O}\right)\right.$ and gallium nitrate $\mathrm{Ga}\left(\mathrm{NO}_{3}\right)_{2}$ in a mixture of the solvents formed by double distilled water, acetic acid and methanol $(25: 10: 65)$ [10]. In order to dope $\mathrm{Ga}$ in $\mathrm{ZnO}$ thin films, five different concentrations $(0.5,1,1.5,2,2.5$ and 3 at $\%$ measured as atomic weight percentage) were selected. The other deposition parameters such as spray rate $\left(5 \mathrm{cc} \mathrm{min}^{-1}\right)$, nozzle to substrate distance $(33 \mathrm{~cm})$ and carrier gas pressure $(2 \mathrm{~atm})$ were kept at their fixed values. The resulting solution $(100 \mathrm{cc})$ was sprayed at an optimized substrate temperature of $673 \mathrm{~K}$. The structural properties were studied by a Philips x-ray diffractometer PW$1710(\lambda, 1.5405 \AA)$ using $\mathrm{Cu}-\mathrm{K}_{\alpha}$ radiation in the span of $10^{\circ}-100^{\circ}$. Surface morphology of the thin film was studied with JEOL JSM 6360 scanning electron microscope (SEM). Optical absorption study was carried out in the wavelength range 300-1100 nm using spectrometer Systronic Model-119. The electrical parameters such as sheet resistance and figure of merit were measured at room temperature by Hall effect set-up, in Van der Pauw configuration, supplied by Scientific Instruments, Roorkee, India. The room temperature PL spectra were recorded using a Perkin-Elmer luminescence spectrometer (model: LS55) equipped with a xenon flash lamp and a grating to select the source of excitation. The excitation and emission spectra were recorded in the fluorescence mode over the wavelength range $225-700 \mathrm{~nm}$.

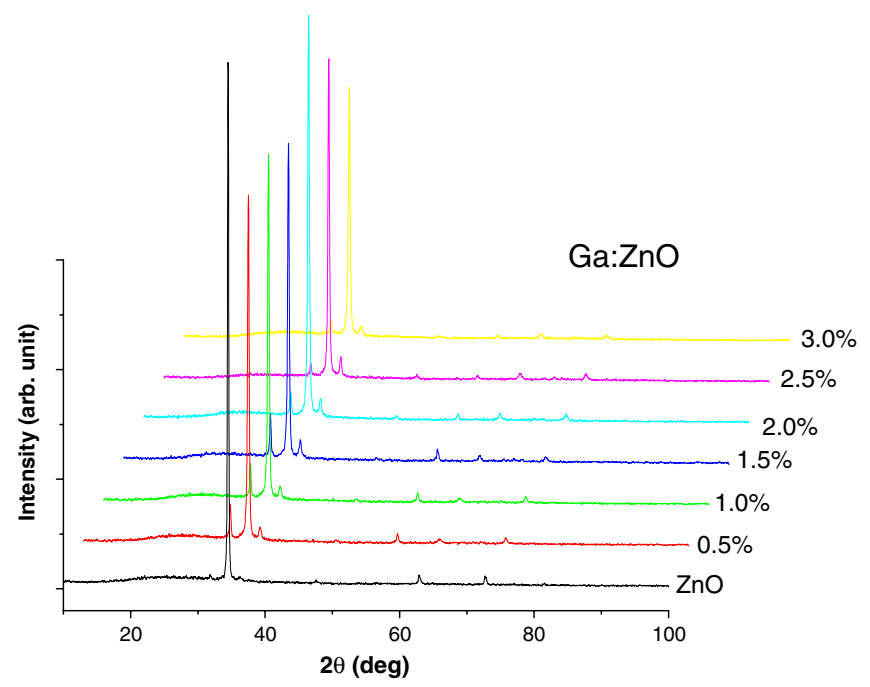

Figure 1. $\mathrm{X}$-ray diffraction patterns of $\mathrm{ZnO}$ and $\mathrm{ZnO}: \mathrm{Ga}$ films prepared with respect to different Ga concentrations (in starting solution).

\section{Results and discussion}

\subsection{X-ray diffraction $(X R D)$ studies}

Figure 1 shows the XRD patterns of undoped and gallium doped zinc oxide thin films grown on glass substrates prepared at a substrate temperature of $673 \mathrm{~K}$ with different gallium concentrations ranging from 0.5 to 3 at $\%$. From the figure it is seen that undoped and doped thin films exhibit hexagonal (wurtzite) crystal structure with a preferential growth along the $\left(\begin{array}{lll}0 & 0 & 2\end{array}\right)$ plane $[10,14]$. The preferred growth of $\left(\begin{array}{lll}0 & 0 & 2\end{array}\right)$ remained predominant irrespective of the gallium-doping level. The intensity of the $\left(\begin{array}{ll}0 & 02\end{array}\right)$ plane has been found to increase with increasing gallium-doping concentration up to 2 at $\%$, which then decreased slightly for the higher doping levels. This may be due to the fact that up to 2 at $\%$ doping $\mathrm{Ga}^{3+}$ ions replace the $\mathrm{Zn}^{2+}$ ions in the $\mathrm{ZnO}$ lattice. However, at higher Ga doping percentages, apart from replacing the $\mathrm{Zn}^{2+}$ ions, $\mathrm{Ga}^{3+}$ ions may occupy the interstitial positions in the $\mathrm{ZnO}$ lattice. Another possible reason for this might be the crystal reorientation effect due to the incorporation of more $\mathrm{Ga}$ atoms. This reorientation effect is not clearly evidenced by XRD studies. For every $\mathrm{Ga}$ atom added to the lattice one extra free electron has been created. As the doping level is increased, more dopant atoms occupy zinc lattice sites, which result in more charge carriers. This process continues as long as there are zinc sites available. However, after a certain level of doping, the Ga atoms cannot occupy zinc lattice sites and they have a tendency to occupy interstitial sites where they form neutral defects and become ineffective as dopant impurities. The exact details of this impurity-defect complex are not fully understood at present. Table 1 shows the comparison of calculated and observed ' $d$ ' values for $\mathrm{ZnO}: \mathrm{Ga}$ thin films. It is observed that they are in good agreement with each other. Therefore, though the substrate temperature is the same, the film formation mechanism and hence the crystallinity changes with Ga doping level. The full-width at half maximum (FWHM) and peak positions of the $\left(\begin{array}{ll}0 & 02\end{array}\right)$ plane with respect to $\mathrm{Ga}$ doping are 
Table 1. Comparison of the calculated and observed ' $d$ ' values for $\mathrm{ZnO}: \mathrm{Ga}$ thin films.

\begin{tabular}{|c|c|c|c|c|c|c|c|c|}
\hline \multirow{2}{*}{$\begin{array}{l}h k l \\
\text { plane }\end{array}$} & \multirow{2}{*}{$\begin{array}{l}\text { Calculated } \\
\text { ' } d \text { ' values } \\
(\AA)\end{array}$} & \multicolumn{7}{|c|}{ Observed ' $d$ ' values for $\mathrm{ZnO}$ doped with $\mathrm{Ga}(\AA)$} \\
\hline & & $0 \%$ & $0.5 \%$ & $1 \%$ & $1.5 \%$ & $2 \%$ & $2.5 \%$ & $3 \%$ \\
\hline$\left(\begin{array}{lll}1 & 0 & 0\end{array}\right)$ & 2.8137 & 2.8137 & 2.8013 & 2.8012 & 2.810 & 2.81 & 2.7990 & 2.8063 \\
\hline$\left(\begin{array}{lll}0 & 0 & 2\end{array}\right)$ & 2.6025 & 2.6001 & 2.5979 & 2.5965 & 2.5975 & 2.5972 & 2.5968 & 2.5924 \\
\hline$\left(\begin{array}{lll}1 & 0 & 1\end{array}\right)$ & 2.4752 & 2.4734 & 2.4754 & 2.4734 & 2.4744 & 2.4685 & 2.4721 & 2.4724 \\
\hline$\left(\begin{array}{lll}1 & 0 & 2\end{array}\right)$ & 1.9106 & 1.905 & 1.9105 & 1.9124 & 1.9092 & 1.9065 & 1.9073 & 1.9005 \\
\hline$\left(\begin{array}{lll}1 & 1 & 0\end{array}\right)$ & 1.6245 & - & 1.6213 & 1.6233 & 1.6236 & 1.6215 & 1.6248 & 1.6213 \\
\hline$\left(\begin{array}{lll}1 & 0 & 3\end{array}\right)$ & 1.4768 & 1.4768 & 1.4749 & 1.4746 & 1.4757 & 1.4745 & 1.4748 & 1.4736 \\
\hline$\left(\begin{array}{lll}0 & 0 & 4\end{array}\right)$ & 1.3012 & 1.2998 & 1.2982 & 1.298 & 1.3003 & 1.2985 & 1.2987 & 1.2979 \\
\hline
\end{tabular}

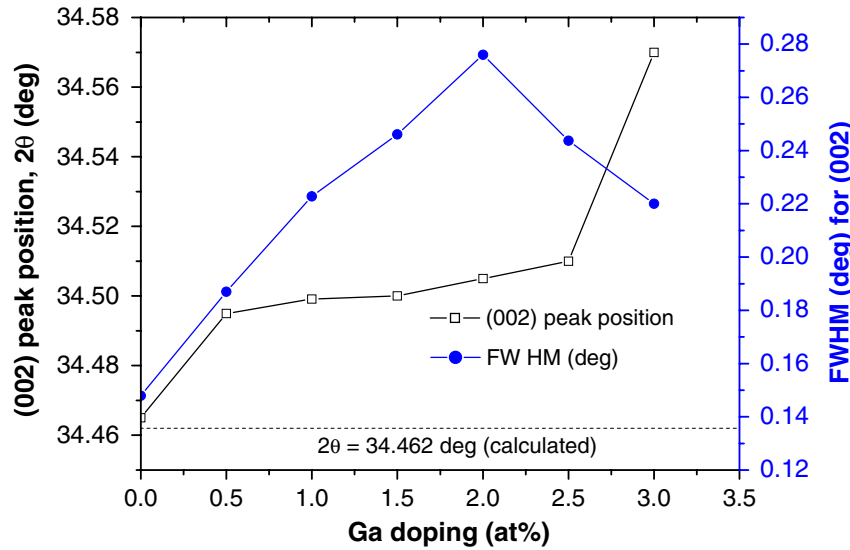

Figure 2. Variation of the $\left(\begin{array}{ll}0 & 0\end{array}\right)$ peak position and FWHM for spray deposited $\mathrm{ZnO}$ : Ga thin films.

shown in figure 2. Observed FWHM was corrected to the corresponding Si single crystal FWHM due to the instrument. It is observed that the $(002)$ peak position continuously deviates from the single crystal value $\left(2 \theta \approx 34.46^{\circ}\right)$ with Ga doping concentration. This is evidence of an increase in relative strain in $\mathrm{ZnO}$ film due to gallium doping. The FWHM values of the $\left(\begin{array}{lll}0 & 02\end{array}\right)$ plane increase with increasing gallium doping up to 2 at $\%$ and then decrease for further gallium doping. This is due to decrease in crystallite size up to 2 at $\%$ gallium doping which increases after 2 at $\%$. The crystallite size ' $D$ ' is calculated using Scherrer's formula [15]

$$
D=\frac{0.94 \lambda}{\beta \cos \theta}
$$

where $D$ is the crystallite size, $\beta$ is the broadening of the diffraction line measured at half of its maximum intensity (rad) FWHM and $\lambda$ is the x-ray wavelength (1.5405 $\AA$ ). It is seen that as doping increases the crystallite size decreases up to 2 at $\%$ and tends to increase afterwards as shown in figure 3. The reflection intensities from each XRD pattern contain information related to the preferential or random growth of polycrystalline thin films which is studied by calculating the texture coefficient $\mathrm{TC}(h k l)$ for all planes using the equation [16]

$$
\mathrm{TC}(h k l)=\frac{I(h k l) / I_{0}(h k l)}{(1 / N) \sum I(h k l) / I_{0}(h k l)},
$$

where $\mathrm{TC}(h k l)$ is the texture coefficient of the $h k l$ plane, $I(h k l)$ is the measured intensity of x-ray reflection, $I_{0}(h k l)$

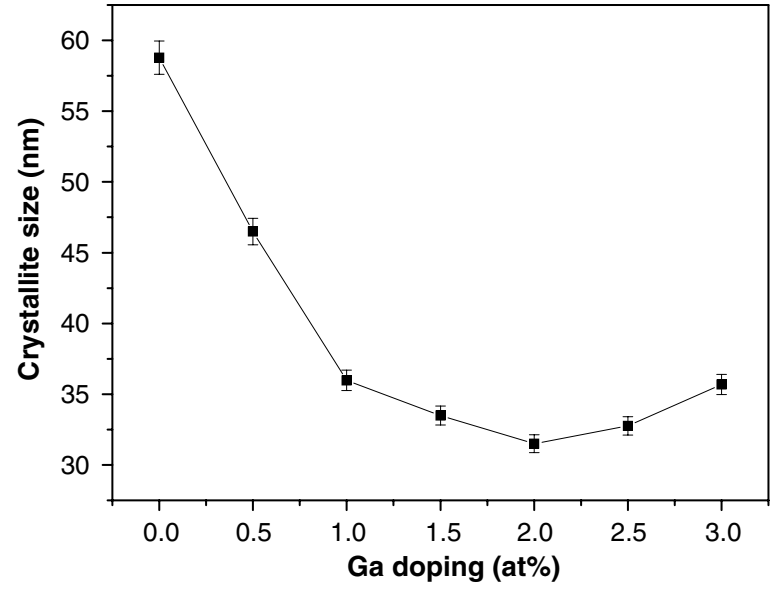

Figure 3. Variation of crystallite size estimated along the ( $\left.\begin{array}{lll}0 & 0 & 2\end{array}\right)$ peak with doping levels of $\mathrm{Ga}$ (in starting solution) for spray deposited $\mathrm{ZnO}: \mathrm{Ga}$ thin films.

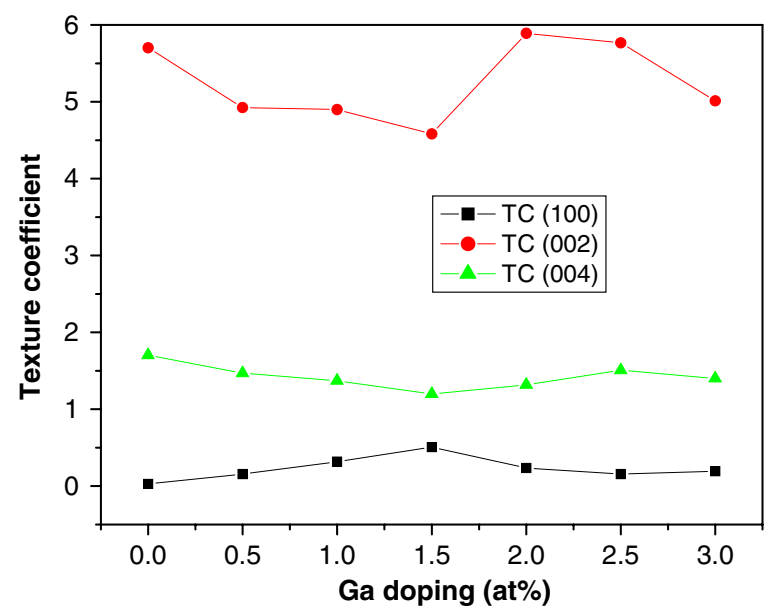

Figure 4. Texture coefficient with different Ga doping concentration (in starting solution) variations for $\mathrm{ZnO}: \mathrm{Ga}$ thin films.

is the corresponding standard intensity from the JCPDS data card No-05-0664 and $N$ is the number of reflections observed in the XRD pattern. Figure 4 depicts the variation of the texture

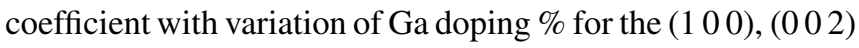
and $(004)$ planes. The texture coefficient for all the films has a relatively $(>1)$ higher value ( 5 to 6$)$ along the $\left(\begin{array}{ll}0 & 0\end{array}\right)$ plane than the other planes: $\left(\begin{array}{lll}1 & 0 & 0\end{array}\right)(<1)$ and $\left(\begin{array}{lll}0 & 0 & 4\end{array}\right)$. TC $\left(\begin{array}{lll}1 & 0 & 0\end{array}\right)$ has the minimum value in all the sprayed thin films. 

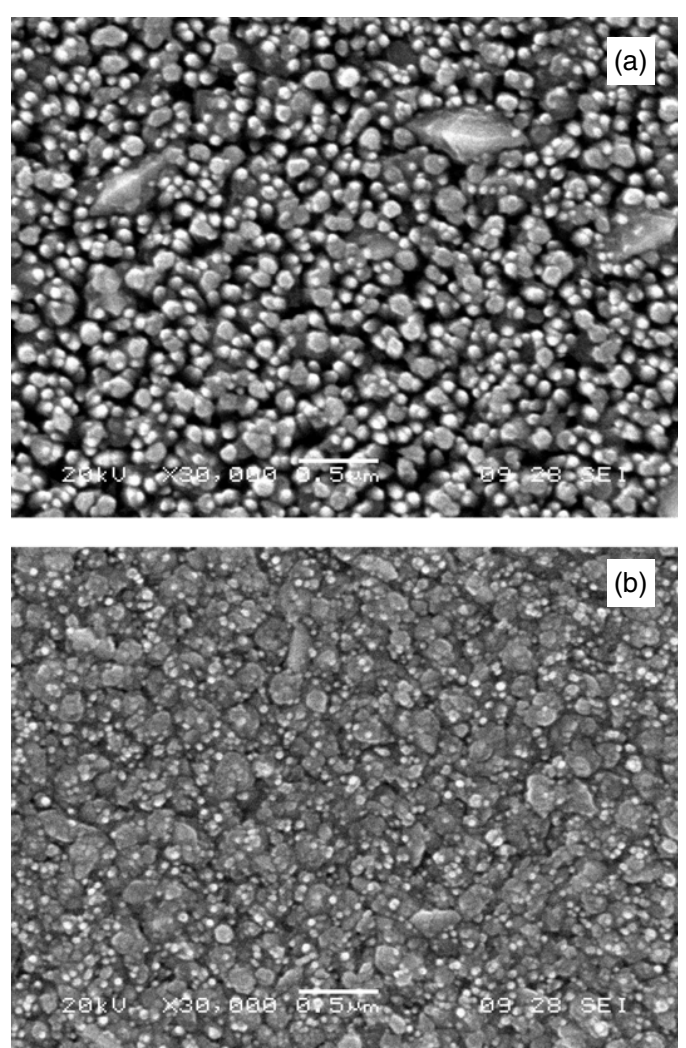

Figure 5. Scanning electron micrographs of (a) $\mathrm{ZnO}$ and $(b) 2$ at $\%$ $\mathrm{ZnO}$ : Ga thin films (magnification: $30000 \times$, bar scale: $0.5 \mu \mathrm{m}$ ).

\subsection{Morphological studies}

The surface morphology of undoped and $\mathrm{Ga}$ doped $\mathrm{ZnO}$ thin films was studied by SEM. The micrograph of the undoped sample (figure 5(a)) shows a textured surface for $\mathrm{ZnO}$ thin film. The textured morphology is a consequence of the nucleation of $c$-axis oriented grains that grow geometrically and impinge laterally. Further it is observed that (figure $5(b)$ ) the grain size decreases for 2 at $\% \mathrm{Ga}$ concentration. The film surface becomes relatively smooth, dense and a mixture of large and small grains that are randomly distributed are visible. This dependence can be attributed to an improved surface diffusion for 2 at $\% \mathrm{Ga}$ concentration. The average grain size estimated from SEM studies for $\mathrm{ZnO}$ samples has been found to be $83 \mathrm{~nm}$, which decreases to $62 \mathrm{~nm}$ after 2 at\% Ga doping, supporting the results from the XRD analysis.

\subsection{Optical properties}

Optical transmission spectra of $\mathrm{ZnO}:$ Ga thin films are depicted in figure 6. The films are uniform and transparent to the naked eye. This is also confirmed by the transmittance spectra of the films. The well-developed interference pattern in $T$ shows that the films are specular to a great extent. The average transparency in the visible range was around $\sim 85$ $95 \%$. Doped samples exhibited increased optical transmission, in the visible region and this is good for device application. The high transparency is associated with a good structural homogeneity and crystallinity. The doping of $\mathrm{ZnO}$ with $\mathrm{Ga}$ results in an increase of transmission in the wider range of

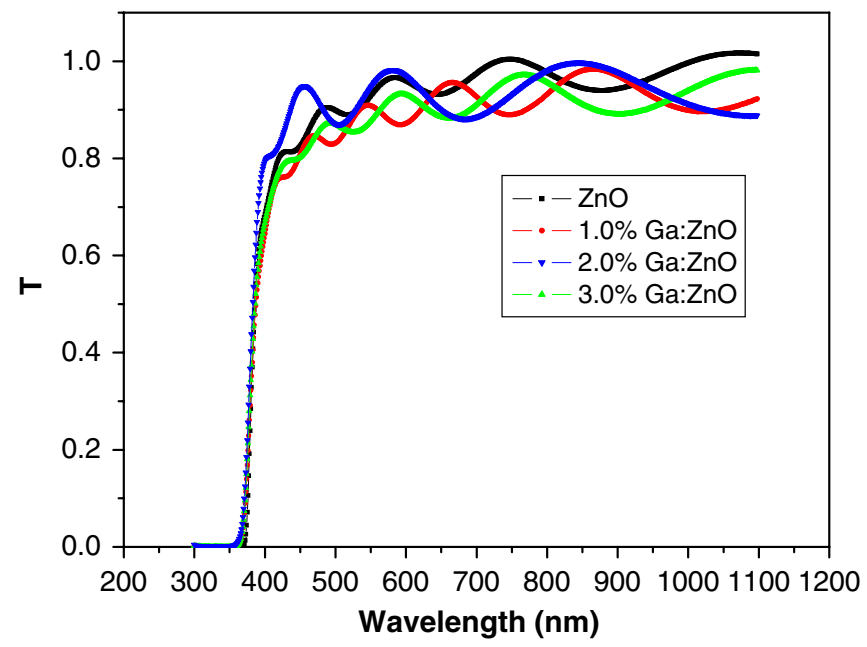

Figure 6. The optical transmission spectra of $\mathrm{ZnO}$ and $\mathrm{ZnO}: \mathrm{Ga}$ thin films prepared with different Ga doping concentrations (in starting solution).

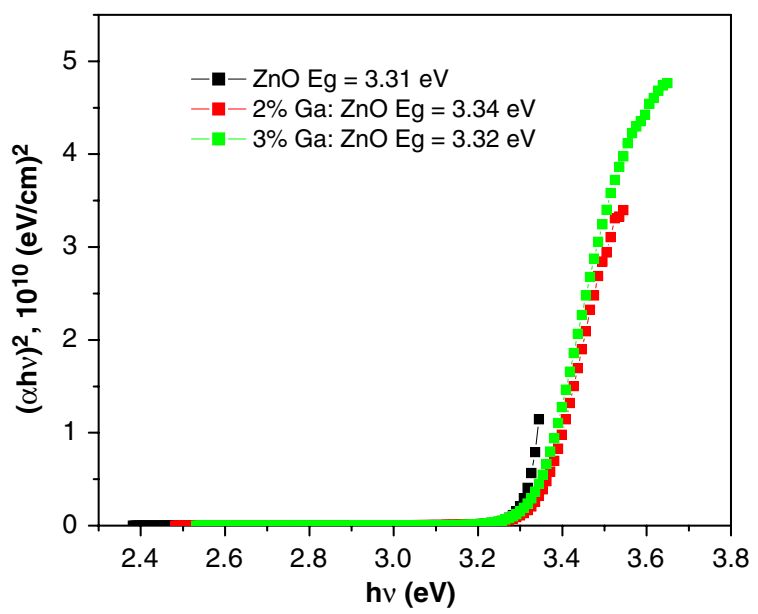

Figure 7. Plot of $(\alpha h v)^{2}$ versus $h v$ for $\mathrm{ZnO}$ and $\mathrm{ZnO}: \mathrm{Ga}(2$ and 3 at\%) thin films.

the solar spectrum. In transparent metal oxides, metal to oxygen ratio and crystal orientation decides the percentage of transmittance. In this case, the formation of $c$-axis oriented grains that grow perpendicular to the substrate surface (SEM studies) are responsible for the increased transparency of the $\mathrm{ZnO}$ : Ga films at 2 at $\% \mathrm{Ga}$. The decrease in transmittance at higher doping concentrations may be due to the increased scattering of photons by crystal defects created by doping. Luminescence is a consequence of doping. In this case up to 2 at $\% \mathrm{Ga}$, the amount of $\mathrm{Ga}$ in the $\mathrm{ZnO}$ lattice increases, thereby increasing the emitted light intensity in the PL. As the film transparency is the highest at 2 at\% Ga, PL brightness is obviously highest at this doping concentration. It can be seen that there is a slight shift of the direct optical transition towards shorter wavelengths, which is due to the Burstein-Moss effect [17] and may be due to scattering by grain boundaries and aggregates.

The plots of $(\alpha h v)^{2}$ versus $h v$ for the $\mathrm{ZnO}:$ Ga films are shown in figure 7. It is seen that the direct optical band gap $\left(E_{g}\right)$ has increased from $3.31 \mathrm{eV}$ (undoped $\mathrm{ZnO}$ ) to $3.34 \mathrm{eV}$ for the film with 2 at $\%$ Ga doping concentration. The band gap 
energy determined in this way is not the actual band gap of the deposit as these are degenerate semiconductors, the Fermi level lies within the conduction band where its position depends on the density of the free electrons. Thus, the values given for the optical band gaps are related to the excitation of the electrons from the valance band to the Fermi level in the conduction band, whereas the actual band gap of the material is related to the excitation of the electrons from the top of the valence band to the bottom of the conduction band. This means that the lifting of the Fermi level into the conduction band of the degenerate semiconductor due to the increase in the carrier density leads to the energy band broadening (shifting).

Thicknesses and refractive indices were computed from the transmission data by using a standard formula [18]. The wavelength dispersion of the refractive index was fitted using the Cauchey coefficients $\mathrm{An}_{0}=1.6062$ and $\mathrm{An}_{1}=56900$. The refractive indices of all the samples varied almost linearly from 1.65 to 2.24 between $1100 \mathrm{~nm}$ and $300 \mathrm{~nm}$, respectively. Deposited films exhibited almost the same thickness ranging between 625 and $675 \mathrm{~nm}$.

\subsection{Figure of merit}

The quality of transparent conducting films can be judged by the figure of merit $(\Phi)$, calculated from the transmittance and sheet resistance (which are inversely proportional to each other) data [19].

$$
\varphi=\frac{T^{10}}{R_{\mathrm{s}}},
$$

where $T$ and $R_{\mathrm{s}}$ are the transmittance at $550 \mathrm{~nm}$ and the sheet resistance, respectively. The higher values of the figure of merit represent the better performance of the transparent conducting film. Usually, the front contacts to the solar cell are metallic grids. While designing grid contacts, one must balance shading effects against electrical resistance losses. An alternative to metallic grid contacts is a TCO layer. The advantage of TCOs is that they are nearly invisible to incoming light, and they form a good bridge from the semiconductor material to the external electrical circuit. Therefore, both the electrical conductivity and the transmittance of TCO film should be as high as possible for application in solar cells. Figure 8 shows the variation of the figure of merit and the sheet resistance with Ga concentration. The $\phi$ increases up to 2 at $\%$ Ga $\left(\sim 3.09 \times 10^{-3} \mathrm{~cm}^{2} \Omega^{-1}\right)$ and then decreases. This value is relatively higher than the value of $5.13 \times 10^{-4} \mathrm{~cm}^{2} \Omega^{-1}$ reported for the spray deposited and vacuum annealed $\mathrm{ZnO}: \mathrm{Ga}$ films [10]. The minimum value of the resistivity observed in this study is $9.375 \times 10^{-3} \Omega \mathrm{cm}$. This is evidence of proper doping of $\mathrm{Ga}$ in $\mathrm{ZnO}$ lattice up to 2 at\% $\mathrm{Ga}$. This value can be decreased by performing further studies on the postdeposition treatments on the $\mathrm{ZnO}: \mathrm{Ga}$ films, such as annealing at optimized temperatures.

\subsection{Photoluminescence}

Room temperature PL excitation and emission for all the samples were measured in the wavelength range $225-700 \mathrm{~nm}$. The excitation spectra (not shown) showed two prominent

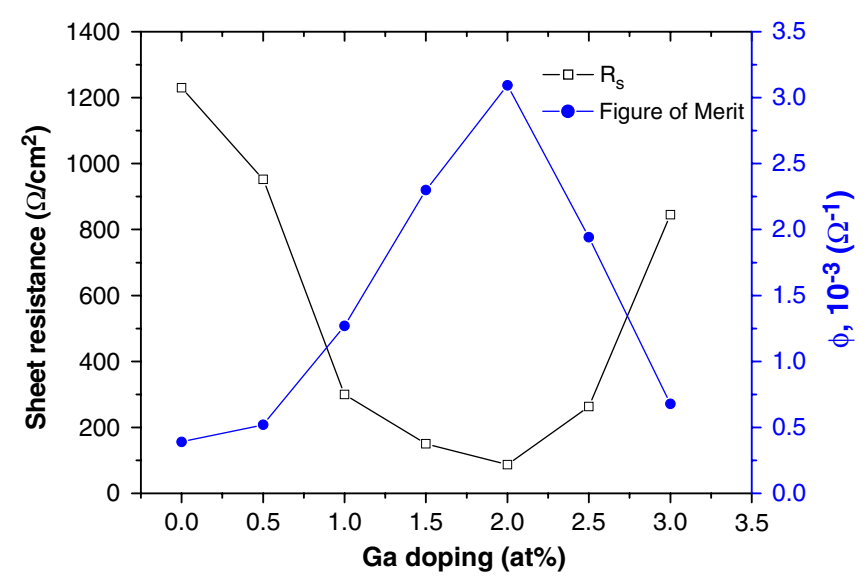

Figure 8. Variation of sheet resistance and figure of merit with gallium-doping concentration (in starting solution) for sprayed $\mathrm{ZnO}$ : Ga thin films.

peaks, one around $324 \mathrm{~nm}(3.8 \mathrm{eV})$ and a shoulder around $240 \mathrm{~nm}(5.2 \mathrm{eV})$, whose positions remained almost the same for all the films. The emission spectra (figure $9(a)$ ) taken at $324 \mathrm{~nm}$ excitation showed a strong violet emission band around $415-420 \mathrm{~nm}$ in all samples, which was slightly blue shifted to $415 \mathrm{~nm}$ in $2 \% \mathrm{Ga}: \mathrm{ZnO}$ thin film. In order to reduce the background noise and resolve the peak shifts each emission spectrum was averaged out for five times at identical conditions. The violet peak centred at $415-420 \mathrm{~nm}$ can be attributed to the $\mathrm{Zn}$ vacancies $[20,21]$. The inset (figure $9(a)$ ) shows the graph of PL intensity versus gallium doping concentration. It is seen that for 2 at $\%$ Ga doping the PL brightness is maximum. Unlike the excitation at $324 \mathrm{~nm}$, the $240 \mathrm{~nm}$ excitation showed a cumulative effect on the visible PL ranging between 430 and $515 \mathrm{~nm}$ (see figure $9(b)$ ). This indicates that both the intrinsic shallow traps $\left(\mathrm{V}_{\mathrm{Zn}}\right)$ and deep level vacancies $\left(\mathrm{Zn}_{\mathrm{i}}, \mathrm{O}_{\mathrm{Zn}}\right.$ and $\left.\mathrm{V}_{\mathrm{o}}\right)$ are being affected in $\mathrm{ZnO}$ [22]. The mechanism of the green emission has been suggested to be mainly due to the concentration of free electrons, and the existence of various point defects identified as $V_{0}$ due to heating treatments or oxidation associated with our process that could have easily formed the recombination centres that resulted [23]. In this case, the strong green emission suggests that $\mathrm{ZnO}$ has point defects, such as oxygen vacancies [24,25], which are considered to be the main source of green light emission in $\mathrm{ZnO}$ thin film.

\section{Conclusions}

The n-type zinc oxide and gallium doped zinc oxide thin films were prepared at $673 \mathrm{~K}$ substrate temperature using the chemical spray pyrolysis technique and the effect of gallium doping on the physical characteristic was studied. The thin films are polycrystalline with hexagonal (wurtzite) crystal structure having a preferred orientation along the $\left(\begin{array}{lll}0 & 0 & 2\end{array}\right)$ plane. The SEM showed that the surface morphology is affected by the $[\mathrm{Ga}] /[\mathrm{Zn}]$ ratios. Oxygen vacancies are the dominant luminescent centres for the emission of green light in $\mathrm{ZnO}$ thin films. Gallium doping leads to a considerable increase in optical transmittance of the $\mathrm{ZnO}: \mathrm{Ga}$ thin films. The 

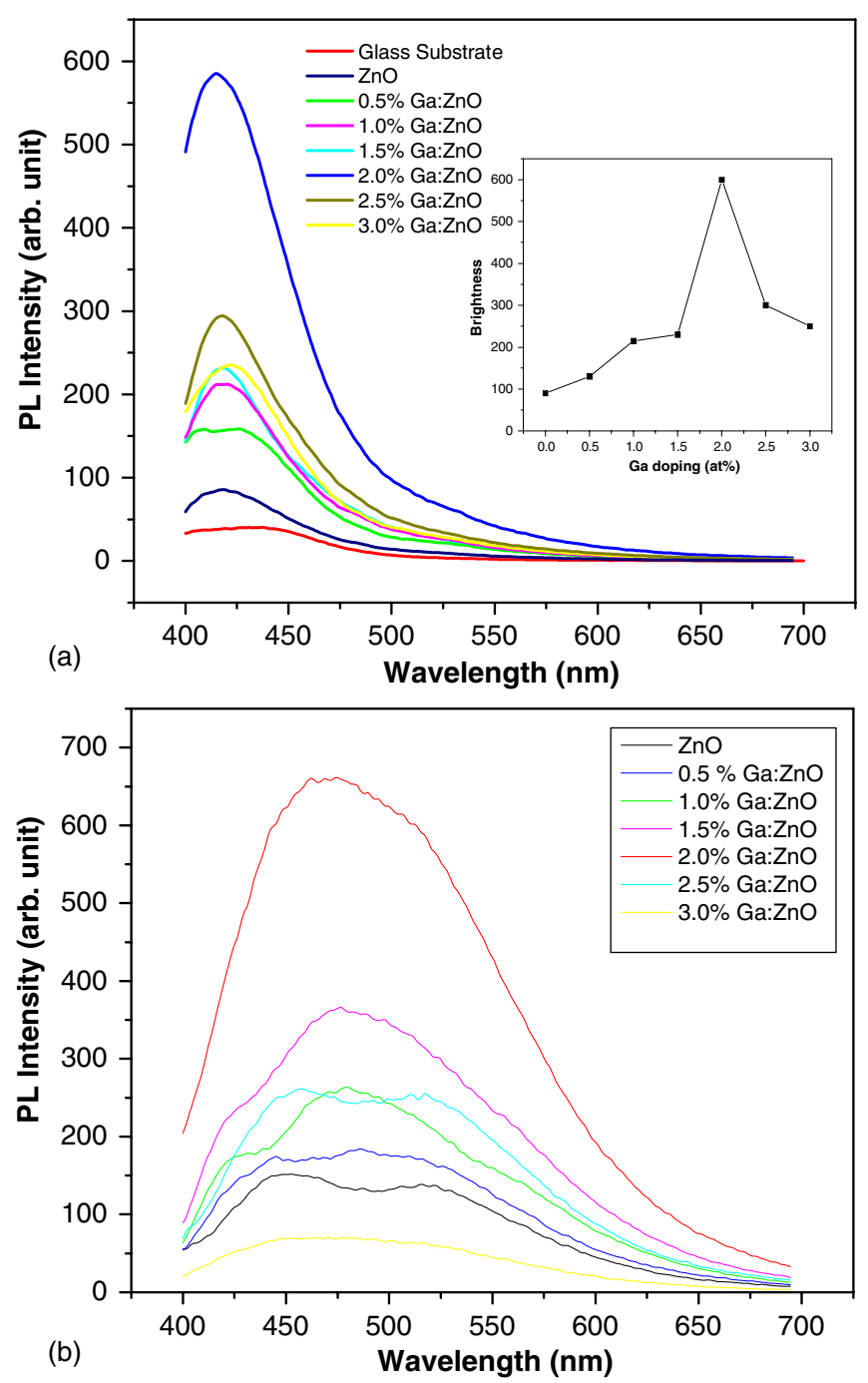

Figure 9. PL emission spectra of $\mathrm{ZnO}$ : Ga thin films with gallium doping concentration (in starting solution) at (a) $324 \mathrm{~nm}$ excitation (the inset shows the plots of PL intensity versus Ga doping concentration) and (b) $240 \mathrm{~nm}$ excitation.

highest figure of merit and the minimum resistivity achieved for $\mathrm{ZnO}$ : Ga thin films has been found to be $3.09 \times 10^{-3} \mathrm{~cm}^{2} \Omega^{-1}$ and $9.37 \times 10^{-3} \Omega \mathrm{cm}$, respectively.

\section{Acknowledgment}

The authors are highly grateful to the University Grants Commission (UGC), New Delhi, and Defence Research and Development Organization (DRDO), New Delhi, for the financial support through the UGC-DRS IInd phase
Programme (2004-2009) and the major research project (No ERIP/ER/0503504/M/01/1007), respectively.

\section{References}

[1] Dutta A and Basu S 1995 J. Mater. Sci.: Mater. Electron. 6 415-8

[2] Riad A S, Mahmoud S A and Ibrahim A A 2001 Physica B 296319

[3] Tüzemen S, Gang Xiong, John Wilkinson, Brian Mischuck, Ucer K B and Williams R T 2001 Physica B 3081197

[4] Özgür Ü, Alivov I Y, Liu C, Teke A, Reshchikov M A, Doan S, Avrutin V, Cho S-J and Morkoç H 2005 J. Appl. Phys. 98041301

[5] Pearton S J, Norton D P, Ip K, Heo Y W and Steine T 2005 Prog. Mater. Sci. 50293

[6] Mandalapu L J, Xiu F X, Yang Z and Liu J L 2007 Solid State Electron. 51 1014-7

[7] Yamada T, Nebiki T, Kishimoto S, Makino H, Awai K, Narusawa T and Yamamoto T 2007 Superlatt. Microstruct. 42 68-73

[8] Ma Q B, Ye Z Z, He H P, Zhu L P, Wang J R and Zhao B H 2007 Mater. Lett. 61 2460-3

[9] Kishimoto S, Hayashi K, Hamaguchi H, Makino H, Yamada T, Miyake A and Yamamoto T 2007 Phys. Status Solidi b 244 1483-9

[10] Gomez H and Olvera M de la L 2006 Mater. Sci. Eng. B $13420-6$

[11] Park S M, Ikegami T, Ebihara K and Shin P K 2006 Appl. Surf. Sci. 253 1522-7

[12] Osada M, Sakemi T and Yamamoto T 2006 Thin Solid Films 494 38-41

[13] Yamamoto T, Sakemi T, Awai K and Shirakata S 2004 Thin Solid Films 451-452 439-44

[14] Powder Diffraction File Alphabetic PDF-2 Data Base, file 05-664 1994 International Center of Diffraction Data Newton Square, PA, USA

[15] Rodríguez-Báez J, Maldonado A, Torres-Delgado G, Castanedo-Pérez R and Olvera M de la L 2006 Mater. Lett. 60 1594-8

[16] Bareet C and Massalski T B 1980 Structure of Metals (Oxford: Pergamon) p 1923

[17] Burstein E 1954 Phys. Rev. 93632

[18] Heavens O S 1964 Physics of Thin Films ed G Hass and R E Thun (New York: Academic) p 203

[19] Haacke G 1976 J. Appl. Sci. 474086

[20] Jeong S H, Kim B S and Lee B T 2003 Appl. Phys. Lett. 822625

[21] Jin B J, Im S and Lee S Y 2000 Thin Solid Films 366107

[22] Studenikin S A and Michael Cocivera 2002 J. Appl. Phys. 915060

[23] Dingle R 1969 Phys. Rev. Lett. 23 579-81

[24] Cao B, Sun F and Cai W 2005 Electrochem. Solid-State Lett. $8 \mathrm{G} 237$

[25] Li Y, Meng G W and Zhang L D 2000 Appl. Phys. Lett. 762011 